\title{
Secondary Stress State around the Bored Hole in Salt
}

\section{Strata}

\author{
Mihaela Toderas
}

Department of Mining Engineering, Surveying and Civil Engineering, The University of Petrosani, Petrosani 332006, Romania

\begin{abstract}
In Romania, rendering the oil structures evident in the deep strata $(\approx 6,000 \mathrm{~m})$ is conditioned by the penetration of some salt deposits of appreciable thickness (500-3,000 m) situated above the structures with petroleum potential. Crossing by the drilling of these salt deposits constitutes a major risk factor both in achievement (drilling, cementing) and afterwards, to ensure the stability-reliability of the wells. Based on these reasons, the researches have been focused on: the study of salt behavior deformation, establishment of the required parameters to ensure the stability of the drillings until the bore-hole lining (especially the secondary stress state around the drilling, the density of the drilling fluid in correlation with the temperature and respectively the depth) and also after casing (type of the cement pastes, the nature, the quality and the dimensions of pipes), namely the reliability of the wells.
\end{abstract}

Key words: Salt, stability, secondary stress state, drilling, pipe, cement paste, temperature, depth.

\section{Introduction}

It is well known that salt is a natural material system characterized by an inelastic behaviour of viscous-elastic-plastic combined type [1]. Salt penetration by drilling especially at high depths (over $1,000 \mathrm{~m}$ ) causes some difficulties. Such difficulties require the application of some special drilling technologies suitable to the salt behavior during the entire period of execution, namely: drilling (hole deflection hazard, that requires a reduced pressure on the bit and therefore a reduced rate of advance; the contact with the drilling fluid unsuitable as composition and density determines the dissolution of salt, leading to the jamming of the drill column, etc.); hole support with drilling fluid (using some fluids that can be effective only when they have a suitable density which can reduce the salt rate of deformation in the hole walls, controlling the closure of the drilling carried out in the salt strata); bore-hole lining and cementing of the pipes (types of cement paste; the quality and dimensions of the pipes) [2,3].

Corresponding author: Mihaela Toderas, Ph.D., associate. professor, research fields: rock mechanics, soil mechanics and underground structures. E-mail: toderasmihaela@yahoo.com.

\section{Method}

Based on the geo-mechanical characterization of salt, salt and the drilling technology, we have analyzed we analyzed: the secondary indirect stress of the salt mass around the bored hole, the type of the boring sludge that can be used and, finally, the dimensioning of the pipes boreholes [4, 5]. Thus, the secondary stress state around the hole drilled in salt has been analyzed in its horizontal plane, assimilating the drill with a cylinder with thick walls having an infinite external radius, filled with drilling fluid. In this case, and taking into account the salt behavior only in the elastic (steady) zone, the secondary stress state around the hole filled with drilling fluid is given by the relations:

$$
\sigma_{r}=\sigma_{x}+\left(p_{i}-\sigma_{x}\right) \frac{a^{2}}{r^{2}} ; \sigma_{\alpha}=\sigma_{x}-\left(p_{i}-\sigma_{x}\right) \frac{a}{r^{2}}
$$

And the difference between the two components tangential $\sigma_{\theta}$ and radial $\sigma_{r}$ is:

$$
\sigma=\sigma_{\theta}-\sigma_{r}=2\left(\sigma_{x}-p_{i}\right) \frac{a^{2}}{r^{2}}
$$

where, $p_{i}$ is the value of the reaction developed by the drilling fluid inside the drilling; $r$ is the distance to the outline towards the inside of the salt mass; $a$ is the 
radius of the bore-hole; $\sigma_{x}$ is the value of the horizontal component of the natural stress state and it is equal with the product $\gamma_{a} H=\sigma_{2}$ during an isometric or hydrostatic (incompressible) stress state, namely $\sigma_{z}$ $=\sigma_{x}=\sigma_{y}=\gamma_{a} H$.

However, with the increase of stress and therefore of the difference between the components of the secondary stress state $\sigma$, the behavior of salt around the drilling becomes inelastic $[3,4,6]$.

In fact, the viscous-plastic behavior of salt creates the difficulties of salt penetration by drillings and it is influenced by: the rate of hole closure; activation energy of the studied salt which is $W_{a}=19.3 \mathrm{kcal} / \mathrm{mol}$; temperature $T$; respectively depth; coefficient of Poisson $\mu=0.5$ (for the hydrostatic state); rheological parameters $\alpha=0.046 ; \beta=0.34$ and, of course, the considered condition of plasticity [7]. The value of stress $\sigma$, respectively of the difference $\left(\sigma_{\theta}-\sigma_{r}\right)$ in the above context, can be established with the relation:

$$
\sigma=\sigma_{\theta}-\sigma_{r}=N \ln \left[\frac{1}{r^{2}} M+\sqrt{\frac{1}{r^{4}} C+1}\right]
$$

where,

$$
N=\frac{200}{\sqrt{3} \cdot \beta} ; \quad M=\xi a^{2} ; \quad C=\xi^{2} a^{4}
$$

and,

$$
\xi=\frac{\sqrt{3}}{1+\mu} \cdot \frac{\stackrel{\varepsilon}{e x p}\left(\frac{W_{a}}{R T}\right)}{7.2 \cdot 10^{3} \cdot \alpha}
$$

where, $R$ is the constant of the ideal gas $(R=1.987$ $\mathrm{cal} / \mathrm{mol} \cdot \mathrm{K})$.

Besides establishing these parameters, it was necessary to correlate the density of drilling fluids salt (i.e., saturated) to the depth (respectively to the temperature) in the context of development of the $p_{i}$ reaction that should practically limit the closure rate of the bore holes. In order to solve these problems and taking into account that the $p_{i}$ reaction and the drilling fluid density $\gamma_{n}$ are dependent on the closure rate of the drilling hole and, implicitly on the depth $H$, respectively the temperature $t$, it results: the value of the reaction developed by the drilling fluid is:

$$
p_{i}=p_{0}-N \int_{0}^{a} \frac{1}{r} \ln \left[\frac{1}{r^{2}}\left(M+\sqrt{r^{4}+C}\right)\right] \mathrm{d} r
$$

and the value of the drilling fluid density is:

$$
\gamma_{n}=1.318-0.10858 \ln H-p_{i}
$$

\section{Results and Discussion}

The geomechanical characterization included the establishment of the physical characteristics, the characteristics of strength, the instantaneous and especially the rheological deformation of salt (creep behavior) (Table 1) [4, 5]. The rheological behaviour of salt has been analyzed by uniaxial compressive tests on salt cylindrical specimens having $1.5<\lambda<2$ examined at $\Delta=10$ degree of stress defined in the (5.145-13.965) MPa range.

In fact, the increase of $\sigma$ is the result of the increase of depth and implicitly of temperature; according to the result of in situ measurements carried out in several drillings (up to a depth of approximately $4,500 \mathrm{~m}$ and a thickness of salt from $1,000 \mathrm{~m}$ to $3,000 \mathrm{~m}$ ), the following correlations could be established:

$$
\begin{gathered}
T=283.42+0.02693 H \quad(\mathrm{~K}) \\
t=9.78+0.02693 H \quad(\mathrm{C})
\end{gathered}
$$

And the transition zone determined by the stress parameter $\sigma$ and depth $H$ through the temperature $t$ (Fig. 1) is given by the relation:

$$
\sigma=61.1-2.65 t
$$

In fact, this zone indicates the salt transition from an elastic-viscous rheological behavior to a viscous-plastic one. Considering the extreme values of the salt deformation rate in the stage of stationary creep (see Table 1), as being equal to 0.01 /hour respectively 0.001 /hour, which we assimilated with rates of closure of the hole walls, according to Eq. (3) the variation of the stress $\sigma$ has been evaluated for the two limits of the parameter ${ }_{\varepsilon}^{\circ}$. The results are presented in Fig. 2.

It can be noticed that in both situations the difference $\left(\sigma_{\theta}-\sigma_{R}\right)$ decreases with the increase of the depth. 
Table 1 Geomechanical characterization of the salt and cement pastes properties.

\begin{tabular}{|c|c|c|c|c|c|c|c|}
\hline \multirow{2}{*}{\multicolumn{3}{|c|}{ Property experimentally determined in laboratory }} & \multirow{2}{*}{ Unit of measure } & \multirow{2}{*}{$\begin{array}{l}\text { Salt } \\
\text { average value }\end{array}$} & \multicolumn{3}{|c|}{ Cement paste (cement formula) } \\
\hline & & & & & I & II & III \\
\hline \multicolumn{3}{|c|}{ Apparent specific weight } & $10^{4} \mathrm{~N} / \mathrm{m}^{3}$ & 2.039 & 1.718 & 1.712 & 1.816 \\
\hline \multicolumn{3}{|c|}{ Uniaxial compressive breaking strength $\sigma_{r c}, \lambda=1.8$} & $\mathrm{MPa}$ & 14.16 & 10.93 & 7.59 & 12.8 \\
\hline \multicolumn{3}{|c|}{ Tensile strength $\sigma_{n}$ by compressive, $\lambda=0.5$} & $\mathrm{MPa}$ & 1.39 & - & - & - \\
\hline \multicolumn{3}{|c|}{ Cohesion $c$ determined by shear } & $\mathrm{MPa}$ & 2.65 & 9.8 & 2 & 8.5 \\
\hline \multicolumn{3}{|c|}{ Internal friction angle by shearing $\varphi$} & degree & 11 & 12 & 30 & 10 \\
\hline \multirow{5}{*}{\multicolumn{3}{|c|}{$\begin{array}{l}\text { Triaxial compressive breaking } \\
\text { strength }\end{array}$}} & $\mathrm{MPa}$ & 22.1 & - & - & - \\
\hline & & & $\mathrm{MPa}$ & 25.3 & 28.6 & 30.5 & 29.1 \\
\hline & & & $\mathrm{MPa}$ & 29.58 & - & - & - \\
\hline & & & $\mathrm{MPa}$ & 33.13 & 37.7 & 42.3 & 39.1 \\
\hline & & & $\mathrm{MPa}$ & 35.43 & - & - & - \\
\hline \multicolumn{3}{|c|}{ Cohesion $c_{t r}$ determined in triaxial } & $\mathrm{MPa}$ & 7.9 & 9.8 & 9.5 & 10 \\
\hline \multicolumn{3}{|c|}{ Internal friction angle $\varphi_{t r}$ determined in triaxial } & degree & 10 & 11.6 & 12 & 12 \\
\hline \multicolumn{3}{|c|}{ Static coefficient of Poisson $\mu$} & - & 0.24 & - & - & - \\
\hline \multicolumn{3}{|c|}{ Stress at dilatation threshold $\sigma_{p d}$} & $\mathrm{MPa}$ & 6.354 & - & - & - \\
\hline \multicolumn{3}{|c|}{ Maximum value of the volumetric deformation $\varepsilon_{v}$} & $\%$ & -1.45424 & - & - & - \\
\hline \multirow{7}{*}{$\begin{array}{l}\text { Rheological } \\
\text { parameters }\end{array}$} & \multirow{2}{*}{ Viscosity coefficients } & $\eta_{1}$ & MPa days & 864 & - & - & - \\
\hline & & $\eta_{2}$ & MPa days & $18,465.8$ & - & - & - \\
\hline & \multicolumn{2}{|c|}{ Long-term strength limit $\sigma_{H d}=\sigma_{p l}$} & $\mathrm{MPa}$ & $4.95-5.60$ & - & - & - \\
\hline & \multicolumn{2}{|c|}{$\begin{array}{l}\text { Rate of deformation in the field of } \\
\text { stationary creep }{ }_{\varepsilon}\end{array}$} & $\% / \mathrm{h}$ & $\begin{array}{l}0.000983 \approx \\
0.001\end{array}$ & - & - & - \\
\hline & \multicolumn{2}{|c|}{ Value of the creep coefficient, $C_{F}$} & - & 0.833 & - & - & - \\
\hline & \multirow{2}{*}{ Rheological coefficients } & $\alpha$ & - & 0.046 & - & - & - \\
\hline & & $\beta$ & - & 0.34 & - & - & - \\
\hline
\end{tabular}

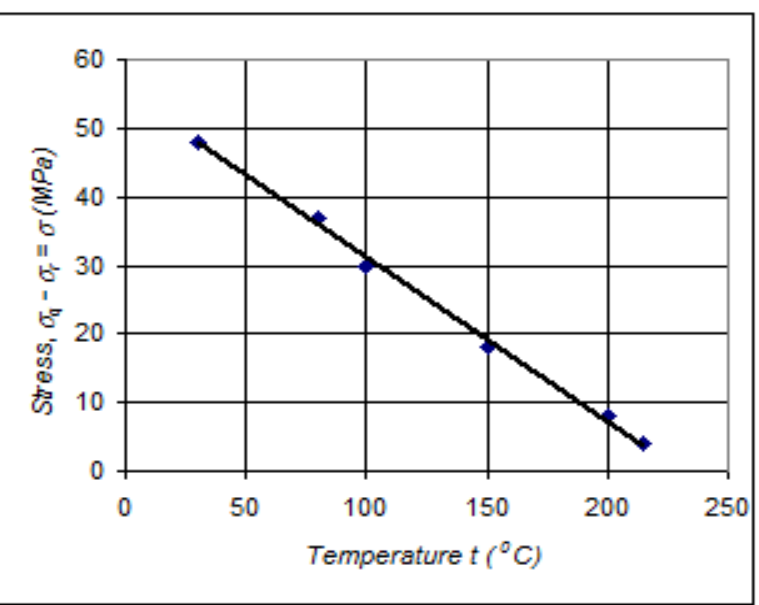

Fig. 1 Stress parameter and depth $H$ through the temperature.

Overlapping the diagram of the transition zone (Curve 3), according to Eq. (8), over the Curves 1 (for $0.001 / \mathrm{h}$ ) and 2 (for $0.01 / \mathrm{h}$ ), it can be conclude that for $0.01 / \mathrm{h}$, the viscous plastic behavior is evident from the depth of $H=1,450 \mathrm{~m}$, while for $0.001 / \mathrm{h}$ such a behavior occurs at the depth of $H=5,500 \mathrm{~m}$.
Therefore, it follows that in order to avoid such viscous-plastic behavior of the salt found between 500 $\mathrm{m}$ to $4,500 \mathrm{~m}$ in depth, where the thicknesses are appreciable, it is necessary to achieve a $p_{i}$ reaction to decrease the closure rate of the hole drilling during the carrying out of the bore-hole and until its casing-off. Only by using the drilling fluid properly both as composition and especially as density we can fulfil such a desideratum [7, 8]. Although the most efficient technical solution would be the utilization of drilling fluids based on petroleum products, these are seldom used because of the financial constraints; they cause serious pollution problems that can hardly be eliminated; they require special preparation - circulation plants and so on. For these reasons correctly dimensioned salty type fluids (i.e., saturated salt fluids) are recommended. These fluids have to be strictly supervised and should have a density corresponding 


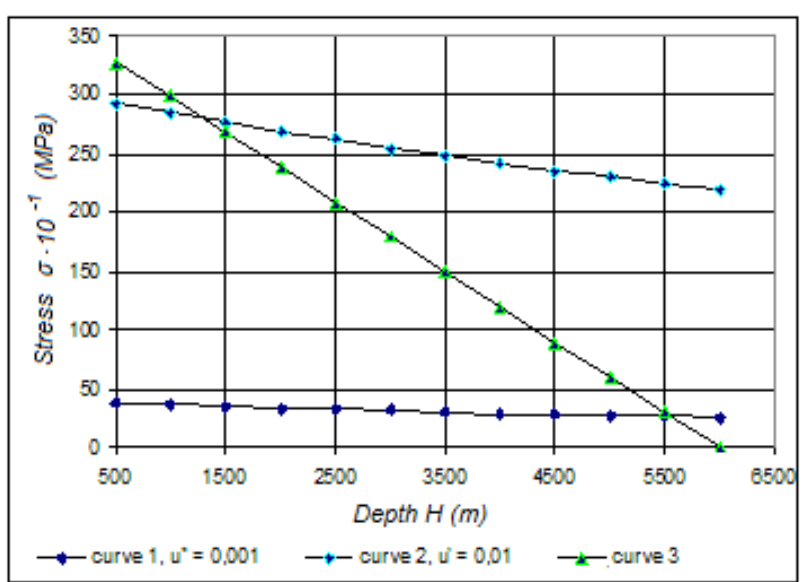

Fig. 2 The $\sigma=\sigma_{\theta}-\sigma_{r}$ stress on the drill hole walls for the studied salt depending on the depth $H$.

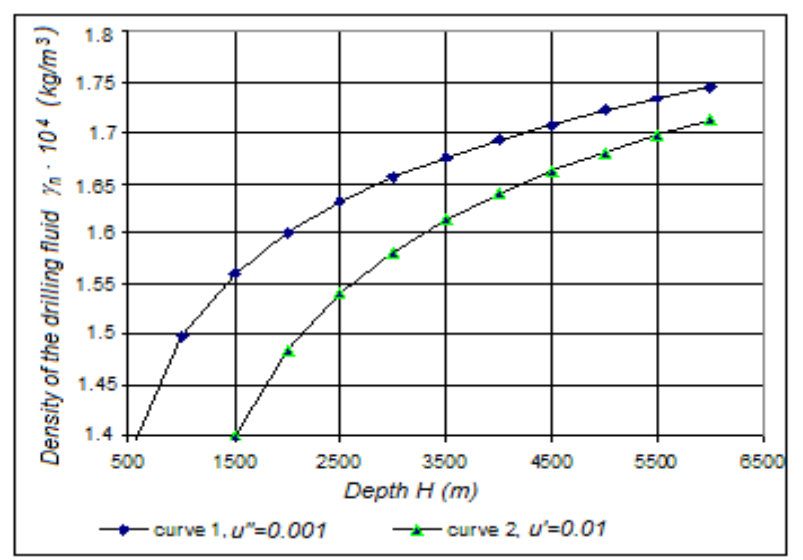

Fig. 3 Graphical correlation between density and depth.

to the following parameters: stress $(\sigma)$, temperature $(t)$, depth $(H)$ and the rheological parameters of the respective salt.

Taking into account the requirements of the drilling process and the further operations (cementing), the Romanian specialists in this field, on the basis of the laboratory studies and by processing the data provided by the 22 wells that used salt-saturated drilling fluids, have established the composition of such fluids, the optimum field of plastic viscosity and the dynamic shear stress depending on density.

Solving Eqs. (4) and (5) by the numerical method of calculus - step by step integration, considering that the upper limit of the integral is equal to $10 \bullet a$, we obtain the graphical correlation (between the density of the drilling fluid and the depth as showed in Fig. 3) for $0.01 / \mathrm{h}$ and $0.001 / \mathrm{h}$ respectively.

In this case, the geothermic modification with the depth was taken into account.

\section{Conclusions}

The results obtained indicate that the closing rate of the hole is generally limited to a value of $0.001 / \mathrm{h}$ and, as a result, if the diameter of the hole is $220 \mathrm{~mm}$ the rate is reduced with $1.3 \mathrm{~mm}$ in $24 \mathrm{~h}$, which is not dangerous in the case of a regular drilling, provided that the density of the drilling fluids of $1.6-1.9 \mathrm{~g} / \mathrm{cm}^{3}$ is observed.

\section{References}

[1] Todorescu, A. 1986. Rheology of Rocks. Bucharest: Technical Publishing House. (in Romanian)

[2] Badea, C., and Buliga, G. 1997. Working out of the Drilling Technology That Penetrates the Massive Salt Rocks. Research Study 3/3. (in Romanian)

[3] Huang, R. 1989. A Study of Viscous-Elastic-Plastic Behavior of Rock Salt and Application in Petroleum Engineering. Balkema, Rotterdam: Rock at Great Depth.

[4] Todorescu, A., and Toderas M. 1997. The Determination of the Geo-mechanic Characteristics of the Halite in Order to Solve the Penetration by Well Holes. Trading Bucharest, S.A.: Research Contract. (in Romanian)

[5] Todorescu, A., and Toderas, M. 1998. Laboratory Experiments for Determination of the Stress Characteristics of the Cement Pastes behind the Well Casing Columns and Possibilities of Increasing the Cement Quality in Thick Salt Strata. Trading Bucharest, S.A.: Research Contract. (in Romanian)

[6] Heard, C. H. 1972. "Steady-State Flow in Polycrystalline Halite at Pressure of 2 kbar." Geophysical Monograph 16: 191-210.

[7] [7] Sereakiov, N. 1971. Circulation Fluids for Drilling in Salts. Nefteanik Publishing.

[8] Darley, H. C. H. 1988. Composition and Properties of Drilling and Completion Fluids. Houston: Gulf Publishing. 